\title{
First-row transitional-metal oxalate resists for EUV
}

\author{
Miles Wilklow-Marnell,, ${ }^{a}$ David Moglia, ${ }^{a}$ Benjamin Steimle, ${ }^{a}$ Brian Cardineau, ${ }^{b}$ Hashim Al-Mashat, ${ }^{a}$ Peter Nastasi, ${ }^{a}$ \\ Kara Heard, ${ }^{\text {a }}$ Amber Aslam, ${ }^{\mathrm{a}}$ Rachel Kaminski, ${ }^{\mathrm{a}}$ Michael Murphy, ${ }^{\mathrm{b}}$ Ryan Del Re, ${ }^{\mathrm{b}}$ Miriam Sortland, ${ }^{\mathrm{b}}$ \\ Michaela Vockenhuber, ${ }^{c}$ Yasin Ekinci, ${ }^{c}$ Robert L. Brainard, ${ }^{b}$ f and Daniel A. Freedman ${ }^{a}$ \\ ${ }^{a}$ State University of New York at New Paltz, New Paltz, New York, United States \\ ${ }^{b}$ State University of New York Polytechnic Institute, Colleges of Nanoscale Science and Engineering, Albany, New York, United States \\ 'Paul Scherrer Institut, Villigen, Switzerland
}

\begin{abstract}
We have developed inorganic oxalate compounds $\left[\mathrm{PPh}_{3}\left(\mathrm{CH}_{2} \mathrm{Ph}\right)\right]\left[\mathrm{M}\left(2,2^{\prime} \text {-bipyridine }\right)_{n}(\text { oxalate })_{(3-n)}\right]$ ( $n=1,2,3 ; \mathrm{M}=\mathrm{Co}, \mathrm{Fe}, \mathrm{Cr}$ ) capable of acting as negative-tone extreme ultraviolet (EUV) resists. Two important trends are observed: (1) sensitivity increases with the number of oxalate ligands; (2) Cobalt and iron complexes exhibit greater sensitivity than analogous chromium complexes. Lithographic studies of the most successful compound, $\left[\mathrm{PPh}_{3}\left(\mathrm{CH}_{2} \mathrm{Ph}\right)\right]\left[\mathrm{Co}\left(2,2^{\prime} \text {-bipyridine)(oxalate) }\right)_{2}\right.$, show that it can consistently achieve $20 \mathrm{~nm} \mathrm{~h} / \mathrm{p}$ lines at doses approaching $30 \mathrm{~mJ} / \mathrm{cm}^{2}$. Infrared, paramagnetic nuclear magnetic resonance, and cyclic voltammetric studies of this compound show that the reaction products of the EUV photochemistry are Co(II)(2,2'-bipyridine) (oxalate) and $\left[\mathrm{PPh}_{3}\left(\mathrm{CH}_{2} \mathrm{Ph}\right)\right]_{2}$ (oxalate) formed from the decomposition of one of the oxalate ligands into two equivalents each of carbon dioxide and electrons. @ 2018 Society of Photo-Optical Instrumentation Engineers (SPIE) [DOI: 10.1117/1 .JMM.17.4.043507]
\end{abstract}

Keywords: EUV; organometallic; resist; Molecular Organometallic Resists for EUV; cobalt; oxalate.

Paper 18110 received Sep. 6, 2018; accepted for publication Nov. 15, 2018; published online Dec. 19, 2018.

\section{Introduction}

For the past 8 years, the photoresist community has seen a great deal of interest in EUV photoresists containing metallic elements. This interest in metal-containing resists was probably initiated by three circumstances: (1) the ground-breaking papers by Amador et al. ${ }^{\mathbb{Q}}$ and Chris Trikeriotis et al. ${ }^{\mathbb{E}}$ demonstrated that hafnium oxide films can act as good EUV photoresists; (2) the realization that capturing more EUV photons will be essential to provide manufacturing

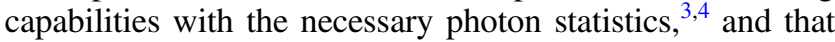
many metals are much more absorbing than the elements (e.g., C, O, N, and F) used in conventional resists; and (3) the maturation of extreme ultraviolet lithography has convinced resist chemists to explore more exotic resist designs. Although metal contamination of integrated circuits continues to remain an open question for the industry, the exploration and discovery of new metal-based resists helps to provide indications of what is lithographically possible with these resist platforms.

Our group has evaluated the utility of creating photoresists out of 10 to 14 metals that exhibit moderate to high EUV absorptivity We call this project, Molecular Organometallic Resists for EUV.

Here we present a design for EUV resists based on firstrow transition-metal oxalates. Our most promising resist, $\left[\mathrm{PPh}_{3}\left(\mathrm{CH}_{2} \mathrm{Ph}\right)\right]\left[\mathrm{Co}(\right.$ bpy $\left.)(\mathrm{ox})_{2}\right]$ (NP1), can be spin-coated to produce high-quality, amorphous films as the pure compound. Exposure to EUV followed by the development in organic solvents produce high-resolution negative-tone dense lines with good sensitivity. Infrared, nuclear magnetic resonance (NMR), and electrochemical experiments provide insight into the mechanism of photochemical reactions that occur during exposure to EUV. In particular, the electrochemical

*Address all correspondence to Robert L. Brainard, E-mail: RBrainard@ SUNYPoly.edu exposures show pathways that can be initiated by reductive (e.g., electron-trapping) or oxidative (e.g., hole-initiated) reactions during EUV exposure.

Transition metal-oxalates have a well-studied history of photochemistry at longer wavelengths than EUV [13 These compounds decompose during UV-Vis photolysis by mechanisms in which the oxalate ligands are converted to $\mathrm{CO}_{2}$ and two electrons [Eq. (1D)]. The two electrons typically reduce the metal center. This reaction is potentially very useful in designing inorganic resists because the reaction is thermodynamically favorable and is simply "triggered" by a photon. Although we have explored several first-row transition metal centers in this report, we have focused on complexes containing $\mathrm{Co}$ (III) because they are significantly more stable toward ligand substitution than other first-row transition metal ions and because cobalt has a relatively high EUV absorptivity.

$\mathrm{C}_{2} \mathrm{O}_{4}^{2-} \rightarrow 2 \mathrm{CO}_{2}+2 \mathrm{e}^{-}$

\section{Results and Discussion}

Here we focus on inorganic complexes of the type $\mathrm{M}(\text { oxalate })_{m}(\text { bpy })_{n}$, where $m+n=3$ and bpy $=2,2^{\prime}$ bipyridine. The identity of the metal was selected between $\mathrm{Co}, \mathrm{Cr}$, and $\mathrm{Fe}$, and the number of oxalate ligand was varied between 0 and 3 . The bipyridine ligand was chosen because it forms very stable metal-ligand bonds, is commercially available, and many derivatives can be purchased or synthesized. Figure 11 shows the compounds that have been prepared for this study.

Counter ions were selected for their ability to create soluble complexes that could be spin-coated to provide high quality coatings. We used benzyltriphenylphosphonium cation $\left(\mathrm{BTP}^{+}\right)$in combination with the anionic metal complexes

$1932-5150 / 2018 / \$ 25.00$ @ 2018 SPIE 


\begin{tabular}{|c|c|c|c|c|}
\hline Compound & $\mathbf{M}=$ & $\begin{array}{l}\text { Coating } \\
\text { solvent }\end{array}$ & $\begin{array}{c}\text { Developing } \\
\text { solvent }\end{array}$ & $\begin{array}{c}\text { Contrast curve } \\
\left(E_{\max }\right)\end{array}$ \\
\hline \multirow{2}{*}{ 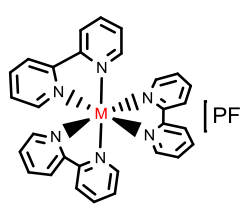 } & Co & $1: 1 \mathrm{AN} / \mathrm{EL}$ & $85 \%$ 2-propanol & $>1000 \mathrm{~mJ} / \mathrm{cm}^{2}$ \\
\hline & $\mathrm{Cr}$ & $1: 1 \mathrm{AN} / \mathrm{EL}$ & $85 \%$ 2-propanol & $>1000 \mathrm{~mJ} / \mathrm{cm}^{2}$ \\
\hline \multirow{3}{*}{ 每 } & Co & $2: 1 \mathrm{AN} / \mathrm{EL}$ & 95\% 2-propanol & $40 \mathrm{~mJ} / \mathrm{cm}^{2}$ \\
\hline & $\mathbf{F e}$ & $2: 1 \mathrm{AN} / \mathrm{EL}$ & $10 \%$ 2-propanol & $\mathrm{n} / \mathrm{a}$ \\
\hline & $\mathrm{Cr}$ & $1: 1 \mathrm{AN} / \mathrm{EL}$ & & $>1000 \mathrm{~mJ} / \mathrm{cm}^{2}$ \\
\hline \multirow{3}{*}{ 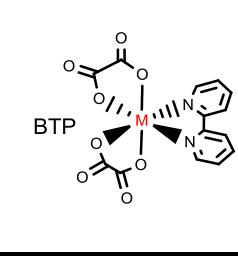 } & Co & $1: 1 \mathrm{AN} / \mathrm{EL}$ & MEK & $8 \mathrm{~mJ} / \mathrm{cm}^{2}$ \\
\hline & $\mathbf{F e}$ & $1: 2 \mathrm{AN} / \mathrm{EL}$ & $\begin{array}{c}1: 1 \\
\text { Acetone:PMA }\end{array}$ & $<15 \mathrm{~mJ} / \mathrm{cm}^{2}$ \\
\hline & $\mathrm{Cr}$ & 1:1 AN/EL & & $35 \mathrm{~mJ} / \mathrm{cm}^{2}$ \\
\hline & Co & $1: 3 \mathrm{AN} / \mathrm{EL}$ & $\begin{array}{c}1: 1 \\
\text { Acteone:PMA }\end{array}$ & $4 \mathrm{~mJ} / \mathrm{cm}^{2}$ \\
\hline
\end{tabular}

Fig. 1 Cobalt, iron, and chromium oxalate compounds prepared in this study (MEK, methyl ethyl ketone; AN, acetonitrile; and EL, ethyl lactate). Samples were spin-coated from freshly prepared solutions ( $2 \%$ to $3 \%$ solids) at $2000 \mathrm{rpm}$ for $60 \mathrm{~s}$ over crosslinked polymer underlayer. Film thicknesses for contrast curves were 50 to $60 \mathrm{~nm}$. Additional details about sample preparation and process are noted in the experimental. All organometallic films were exposed to at least $1000 \mathrm{~mJ} / \mathrm{cm}^{2}$ during open frame (contrast curve) exposure studies. If a sample did not show a measurable imaging response, the $E_{\max }$ value is reported as $>1000 \mathrm{~mJ} / \mathrm{cm}^{2}$.

and used hexafluorophosphate anion $\left(\mathrm{PF}_{6}^{-}\right)$in combination with the cationic complexes.

Contrast curves for three of these compounds are shown in Fig. 2. These all show fairly classic behavior for a negative tone resist with an approximately linear increase in film thickness with exposure dose, reaching a plateau. A range of $E_{\max }$ values for several compounds are shown in Fig. 1.

Several interesting trends in sensitivity are observed (Fig. 11). First, we see a consistent and dramatic improvement in sensitivity as the number of oxalate ligands increases from zero $\left(\left[\mathrm{Co}(\mathrm{bpy})_{3}\right]^{3+}\right)$ to three $\left(\left[\mathrm{Co}(\mathrm{ox})_{3}\right]^{3-}\right)$. The trisbipyridine complex is essentially inert while the trisoxalate complex is remarkably sensitive, reaching an $E_{\max }$ at $<5 \mathrm{~mJ} / \mathrm{cm}^{2}$. Additionally, the complex, $\left[\mathrm{PPh}_{3}\left(\mathrm{CH}_{2} \mathrm{Ph}\right)\right]$ $\left[\mathrm{Co}(\right.$ bpy $\left.)(\mathrm{ox})_{2}\right]$ (NP1), is significantly more sensitive than the analogous chromium complex.

Lithographic studies were performed at Paul Scherrer Institute (PSI) for $\left[\mathrm{PPh}_{3}\left(\mathrm{CH}_{2} \mathrm{Ph}\right)\right]\left[\mathrm{M}(\mathrm{bpy})(\mathrm{ox})_{2}\right]$, where $\mathrm{M}=\mathrm{Co}(\mathrm{III}), \mathrm{Fe}(\mathrm{III})$, and $\mathrm{Cr}(\mathrm{III}) . \square$ Figure 3 shows 35-nm $\mathrm{h} / \mathrm{p}$ lines for $\left[\mathrm{PPh}_{3}\left(\mathrm{CH}_{2} \mathrm{Ph}\right)\right]\left[\mathrm{M}\left(\mathrm{C}_{2} \mathrm{O}_{4}\right)_{2}(\mathrm{bpy})\right](\mathrm{M}=\mathrm{Cr}$, $\mathrm{Fe}$, and $\mathrm{Co})$. The approximate $E_{\text {size }}$ values are consistent with the order of sensitivity observed from their contrast curves (from best to worst: $\mathrm{Co}>\mathrm{Fe}>\mathrm{Cr}$ ). This trend in sensitivity seems to be well-correlated with the thermal decomposition temperatures of the tris-oxalates compounds of the same metals observed by Tanaka et al $\$$ They found that the temperature in which the oxalate decomposed for the metals $\mathrm{Co}, \mathrm{Fe}, \mathrm{Cr}$ were 120,250 , and $345^{\circ} \mathrm{C}$, respectively. They attributed this trend to changes in the ease of reduction of the $\mathrm{M}(\mathrm{III})$ ion, which are generally in the order $\mathrm{Co}(\mathrm{III})>\mathrm{Fe}(\mathrm{III})>\mathrm{Cr}(\mathrm{III})$. This is exemplified by the reduction potentials for the $\mathrm{M}(\mathrm{III})_{(\mathrm{ag})}$ ions, which are $+1.92,+0.77$, and $-0.41 \mathrm{~V}$, for $\mathrm{Co}(\mathrm{III})_{(\mathrm{aq})}, \mathrm{Fe}(\mathrm{III})_{(\mathrm{aq})}$, and $\mathrm{Cr}(\mathrm{III})_{(\mathrm{aq})}$, respectively. We also note that cobalt has the highest EUV cross section and chromium has the least. As discussed in our paper on EUV optical density, $\mathbb{1}_{\text {we }}$ think that the differences in optical density between these compounds are fairly small, so we propose that the reduction potential has a stronger influence in determining their EUV photosensitivity.

The cobalt complex, $\left[\mathrm{PPh}_{3}\left(\mathrm{CH}_{2} \mathrm{Ph}\right)\right]\left[\mathrm{Co}(\text { bpy })_{2}\right.$ (ox) (NP1), provides the best EUV imaging. This complex can image half-pitch lines down to a resolution of $22 \mathrm{~nm}$ with reasonable line edge roughness (LER) and dose (Fig. (1). This resist was developed with methyl ethyl ketone (MEK), which appears to dissolve away the starting material, leaving behind the relatively insoluble EUV photoproduct. 

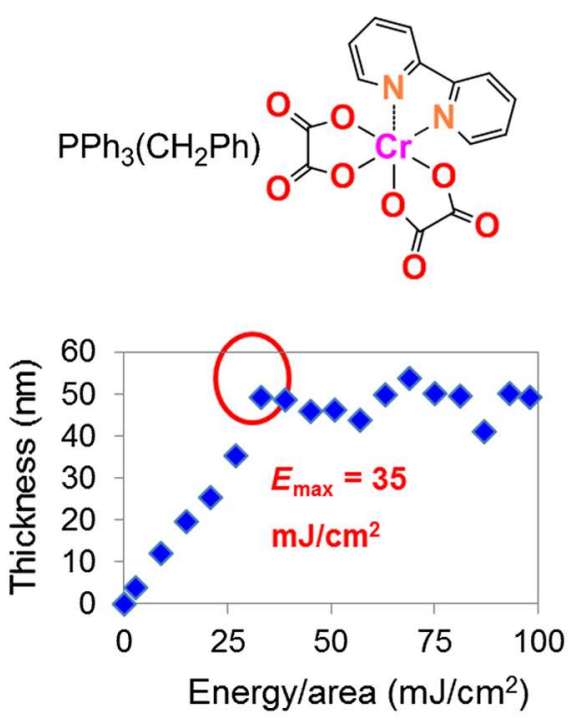
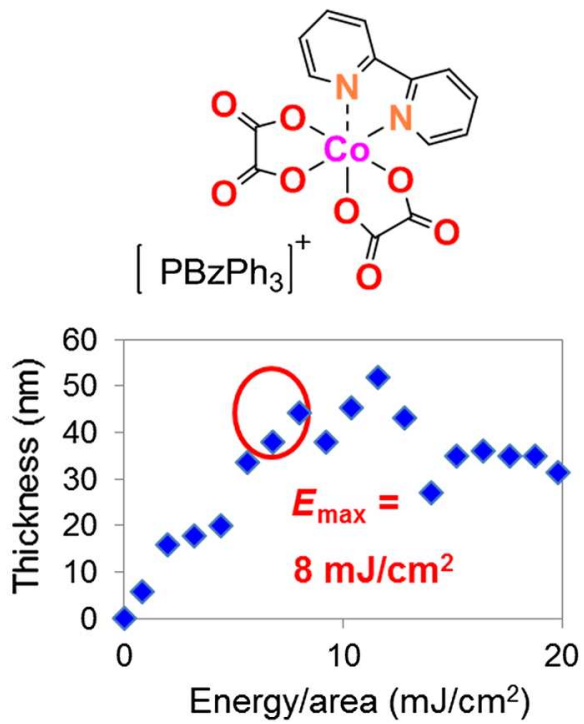
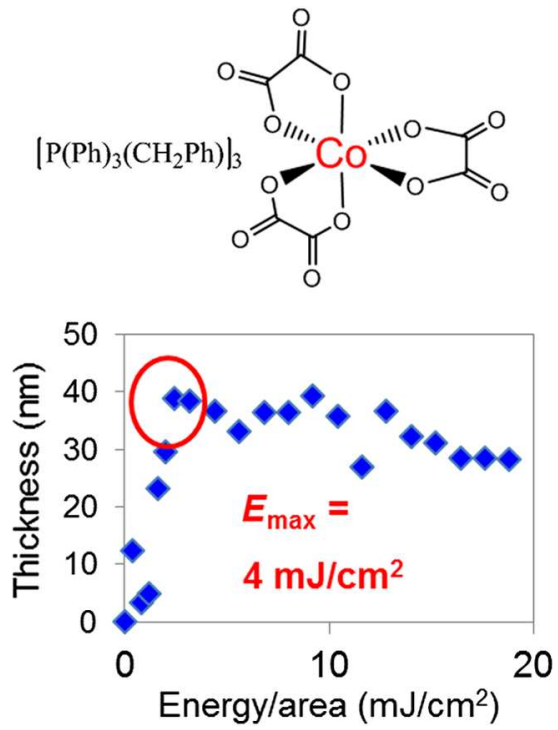

Fig. 2 Contrast curves measured by profilometry for cobalt oxalate complexes.

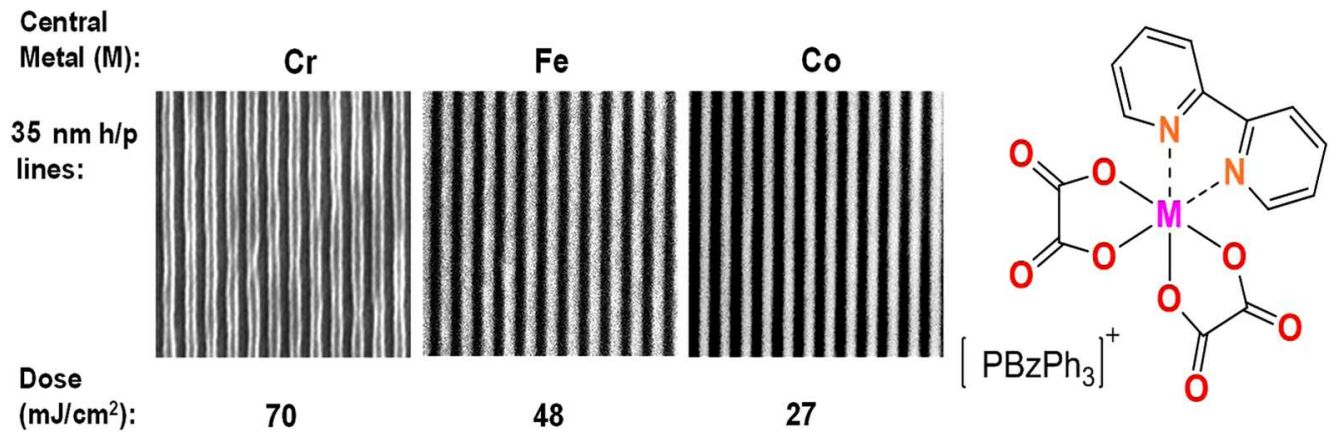

Fig. 3 Lithographic performance of $\left[\mathrm{PPh}_{3}\left(\mathrm{CH}_{2} \mathrm{Ph}\right)\right]\left[\mathrm{M}\left(\mathrm{C}_{2} \mathrm{O}_{4}\right)_{2}(\mathrm{bpy})\right]$ compounds.

As Fig. 5 shows, the resist is not particularly sensitive to the development time, indicating that the solubility contrast between the starting material and photoproduct is large.

\subsection{Photolysis Products of $\left[\mathrm{PPh}_{3}\left(\mathrm{CH}_{2} \mathrm{Ph}\right)\right]\left[\mathrm{Co}\left(\mathrm{C}_{2} \mathrm{O}_{4}\right)_{2}(\right.$ bpy $\left.)\right](\mathrm{NP} 1)$}

It can be quite challenging to determine the solid-state products of EUV photolysis of metal-containing photoresists. Volatile products can typically be identified using massspectroscopy during exposure, but the nonvolatile products are in very thin films in quantities typically $<1 \mathrm{mg}$, and no single spectroscopic technique is capable of telling the whole story.

In this section, we use visible exposure of relatively large quantities of NP1 ( 200 mg) as a model for the photochemical reactions that occur during exposure to EUV light. The technique provides sufficiently large samples of photoproducts to allow for detailed analysis using IR or NMR, and allows direct comparison with authentic samples of the suspected photoproduct synthesized independently. While we recognize the very real possibility that exposure to UV-Vis light will yield different nonvolatile products than will exposure to EUV light, the wealth of information available using longer wavelengths can provide useful information about the photochemical reactions occurring at EUV, as long as the results are interpreted with care. For both UV and EUV wavelengths, we propose that NP1 undergoes reactions specifically driven by the oxidation of oxalate to form $\mathrm{CO}_{2}$ [Eq. (11)]. Specifically, we propose a balanced reaction for the photochemical reactions occurring with both UV and EUV, in which one molecule of NP1 produces one equivalent of $\mathrm{CO}_{2}$, one half equivalent of the salt $\left(\mathrm{PPh}_{3} \mathrm{CH}_{2} \mathrm{Ph}\right)_{2}\left(\mathrm{C}_{2} \mathrm{O}_{4}\right)(2)$, and an oligomeric, paramagnetic compound $\left[\mathrm{Co}(\mathrm{II})\left(\mathrm{C}_{2} \mathrm{O}_{4}\right) \text { (bpy) }\right]_{n}$ (3) (Fig. 6). Described below are mass-spectral, infrared, and NMR data in support of this balanced reaction.

Mass-spectroscopy (EUV and e-beam). The production of $\mathrm{CO}_{2}$ by photolysis of NP1 is consistent with the welldocumented, long-wavelength photochemistry of transition metal oxalates 10 Additionally, Grzeskowiak et al. 1 clearly demonstrated that the exposure of NP1 produced $\mathrm{CO}_{2}$ as the only volatile product upon exposure to either EUV or $80 \mathrm{eV}$ electrons.

Infrared spectroscopy (UV-Vis and EUV). A slurry of $\sim 200 \mathrm{mg}$ of solid NP1 in hexanes was exposed to the pyrex filtered output of a 200-W Hg vapor lamp for $6 \mathrm{~h} . \square$ Upon exposure to UV, the dark-red NP1 is converted to an orange powder, which we propose is a $1: 1$ mixture of $(\mathrm{BTP})_{2}\left(\mathrm{C}_{2} \mathrm{O}_{4}\right)$ (2) and $\left[\mathrm{Co}(\mathrm{II})\left(\mathrm{C}_{2} \mathrm{O}_{4}\right)(\text { bpy) }]_{n}\right.$ (3) (Fig. 6). Compound $\mathbf{3}$ is a known compound; therefore, we were able to synthesize it using a literature procedure. The infrared 


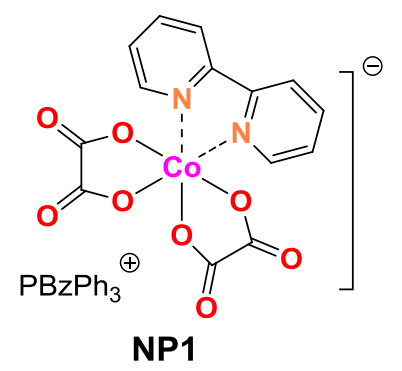

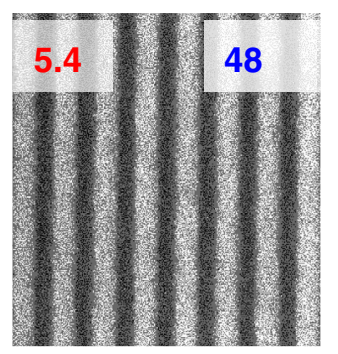

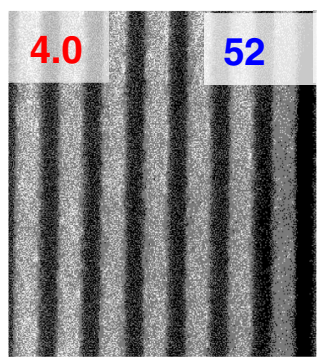

50

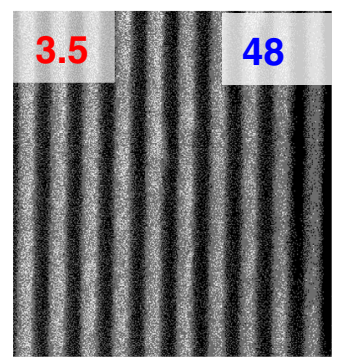

35

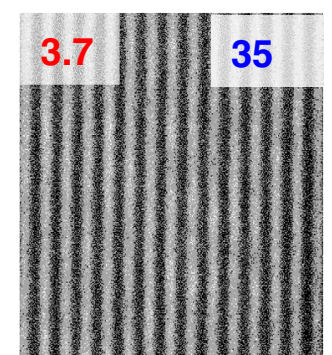

25
Dev. $=$ MEK/15 s

Thickness $=29 \mathrm{~nm}$

$\mathrm{PAB}=90 \% \mathrm{~s} \mathrm{~s}$ PEB $=$ None

$\mathrm{h} / \mathrm{p}$ CD (nm)

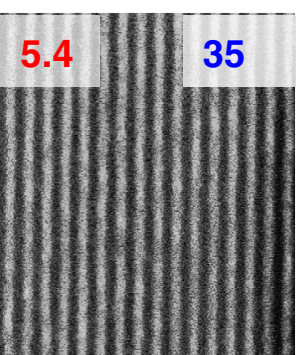

22
Dose $\left(\mathrm{mJ} / \mathrm{cm}^{2}\right)$
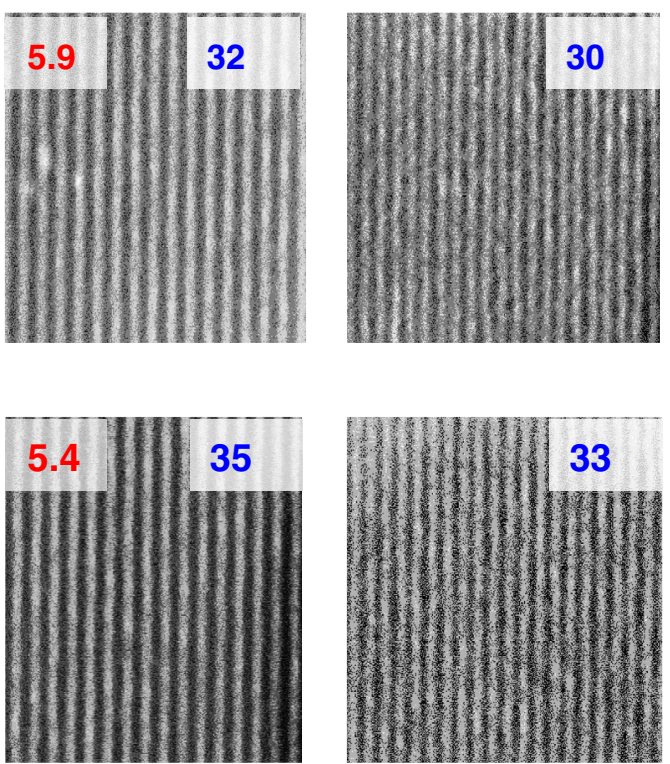

18

Fig. 4 Lithographic performance of $\left[\mathrm{PPh}_{3}\left(\mathrm{CH}_{2} \mathrm{Ph}\right)\right]\left[\mathrm{M}\left(\mathrm{C}_{2} \mathrm{O}_{4}\right)_{2}(\mathrm{bpy})\right]$.

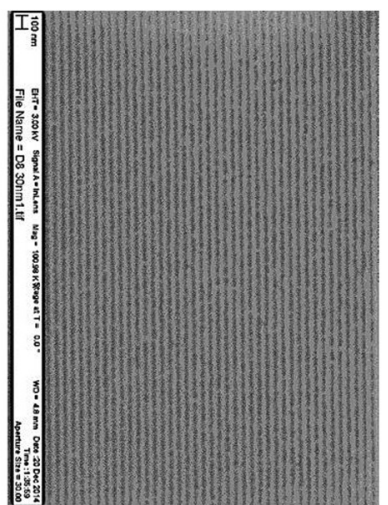

MEK development

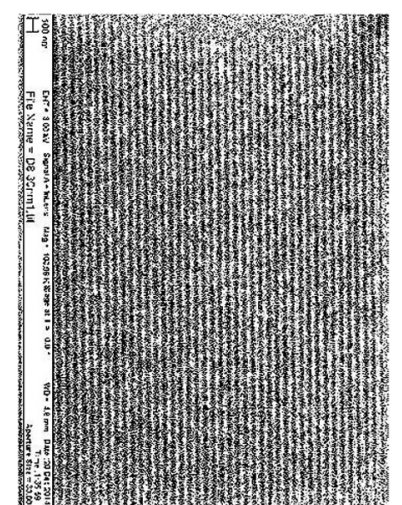

$15 \mathrm{~s}$

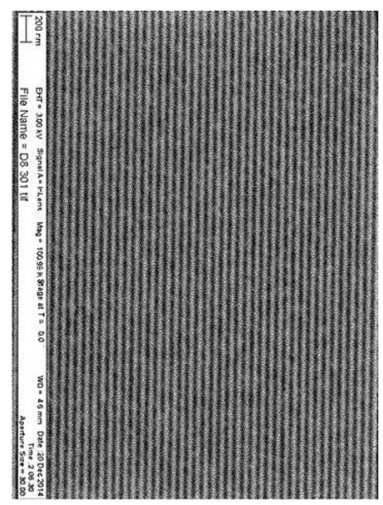

$3 \mathrm{~s}$

Fig. 5 Development time study of $\left[\left(\mathrm{CH}_{2} \mathrm{Ph}\right) \mathrm{PPh}_{3}\right]\left[\mathrm{Co}\left(\mathrm{C}_{2} \mathrm{O}_{4}\right)_{2}(\mathrm{bpy})\right]$ (NP1) with MEK; resolution = $30 \mathrm{~nm} \mathrm{~h} / \mathrm{p}$; dose $=12 \mathrm{~mJ} / \mathrm{cm}^{2}$.

spectrum of compound $\mathbf{3}$ was not a direct match to that of the orange solid mentioned above since the orange photoproduct contains both compounds $\mathbf{2}$ and $\mathbf{3}$. However, when the orange photoproduct was washed with methanol to remove the $(\mathrm{BTP})_{2}\left(\mathrm{C}_{2} \mathrm{O}_{4}\right)(2)$, the remaining solid (dark orange) produced an IR spectra, which was nearly identical to the independently synthesized compound $\mathbf{3}$ [Fig. 7(a)]
The single crystal $\mathrm{x}$-ray structure of $[\mathrm{Co}(\mathrm{II})(\mathrm{bpy})$ $\left.\left(\mathrm{C}_{2} \mathrm{O}_{4}\right)\right]_{n}$ (3) provides insight into its insolubility. The compound is a coordination polymer with oxalates bridging between adjacent $\mathrm{Co}$ (II) sites. In order to dissolve this material, a coordinating solvent is needed to break the cobalt-oxalate bonds. This structure is, therefore, consistent with NP1 acting as a negative-tone resist. 


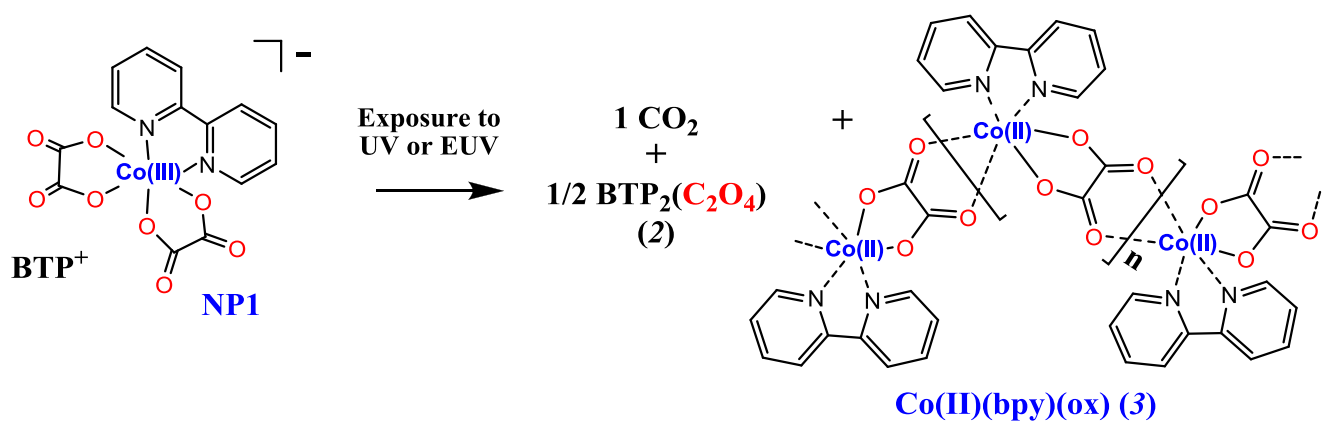

Fig. 6 Proposed balanced equation for the photolysis of NP1 by UV and EUV light; $\mathrm{BTP}^{+}, \mathrm{PPh}_{3} \mathrm{CH}_{2} \mathrm{Ph}^{+}$.
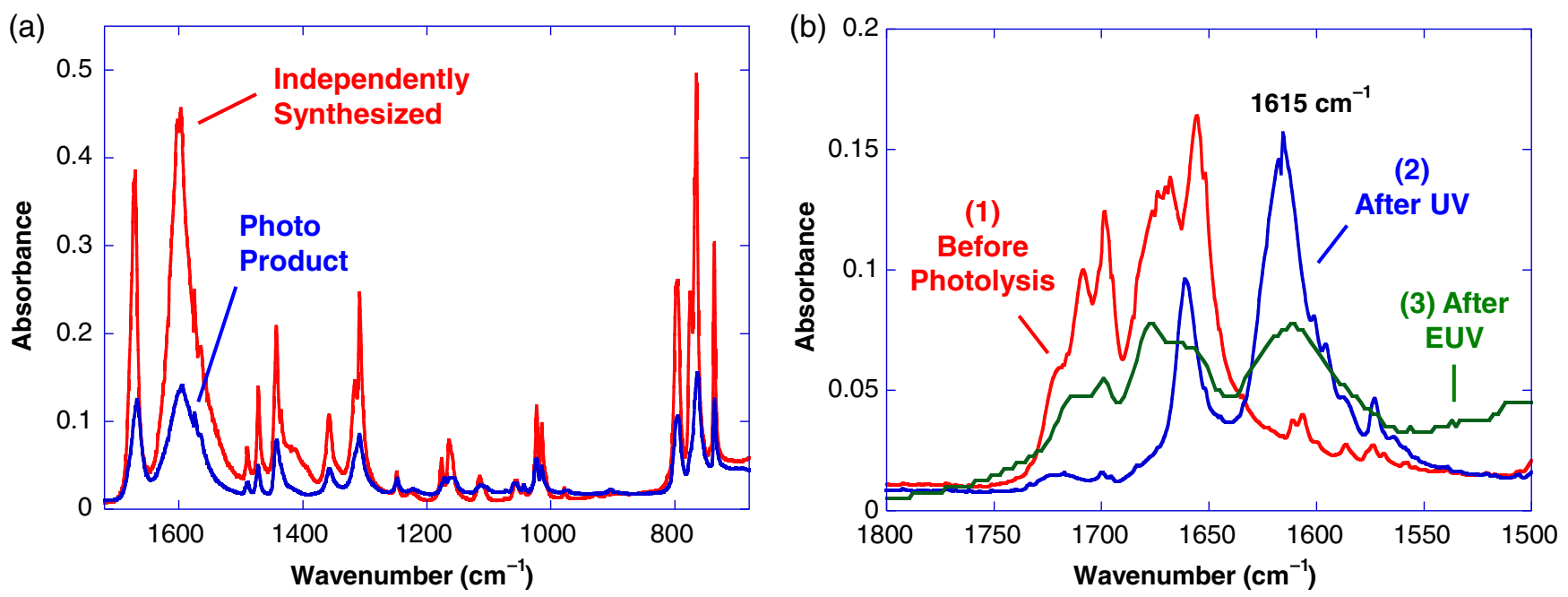

Fig. 7 (a) IR spectrum of a independently synthesized sample of $\mathrm{Co}$ (bpy)(ox) (red) and the photoproduct of $\left[\mathrm{PPh}_{3}\left(\mathrm{CH}_{2} \mathrm{Ph}\right)\right]\left[\mathrm{M}\left(\mathrm{C}_{2} \mathrm{O}_{4}\right)_{2}\right.$ (bpy)] (blue). (b) Solid state infrared spectra of $\left[\mathrm{PPh}_{3}\left(\mathrm{CH}_{2} \mathrm{Ph}\right)\right]$ $\left[\mathrm{Co}\left(\mathrm{C}_{2} \mathrm{O}_{4}\right)_{2}\right.$ (bpy)] and its UV-Vis and EUV photolysis products. (1) Red, before photolysis; (2) blue, after UV-Vis photolysis, and (3) green, after EUV photolysis.

Figure $7(\mathrm{~b})$ shows three IR spectra in the $\mathrm{C}=\mathrm{O}$ oxalate stretching region. Comparisons are made between: (1) a powder sample of NP1 after exposure to UV and (2) a powder sample of NP1 after exposure to UV and extraction with methanol. A third spectrum (3) was acquired by exposing a thin film $(\sim 60 \mathrm{~nm})$ of $\mathbf{N P 1}$ on a silicon wafer to EUV, and then acquiring the IR spectrum through the wafer. The IR of NP1 (1) shows a complex set of vibrations, consistent with its two sets of oxalate ligands. The simple two-peak spectrum (2) of the UV-exposed and methanol-extracted sample is consistent with compound $\mathbf{3}$ since it only contains one oxalate ligand. Of particular interest is the pronounced absorption at $1615 \mathrm{~cm}^{-1}$ since this peak is significantly lower in energy than would be expected for an oxalate ligand coordinated in a bidentate fashion as in NP1 ${ }^{\mathbb{Q}}$ This lowenergy absorption is characteristic of oxalate ligands that bridge between two metal centers in a tetradentate fashion as shown for compound 3 in Fig. 6.9 [1]

Although spectrum (3) of the EUV-exposed sample is not identical to spectrum (2), it does contain a strong peak at $1615 \mathrm{~cm}^{-1}$ as in spectrum (2). Spectrum (3) also contains broad peaks at 1640 to $1725 \mathrm{~cm}^{-1}$. We assign these broad peaks to the oxalate species in unreacted NP1 as well as the $\mathrm{BTP}_{2} \mathrm{ox}(2)$ salt, which should be in this film.
Paramagnetic ${ }^{1} H$ NMR. The NP1 visible light photoproduct was analyzed using ${ }^{1} \mathrm{H}$ NMR without washing with methanol (Fig. (8). According to Fig. 9, this solid should contain both $\left[\mathrm{Co}(\mathrm{II})(\mathrm{bpy})\left(\mathrm{C}_{2} \mathrm{O}_{4}\right)\right]_{n} \quad(3)$ and salt $\left(\mathrm{PPh}_{3} \mathrm{CH}_{2} \mathrm{Ph}\right)_{2}\left(\mathrm{C}_{2} \mathrm{O}_{4}\right)(2)$. The ${ }^{1} \mathrm{H}$ NMR spectrum clearly shows that the four, nonequivalent protons on the bipyridine ligand have shifted dramatically from their normal chemical shift of $7.5 \mathrm{ppm}$ to 15 to $100 \mathrm{ppm}$, whereas the hydrogens

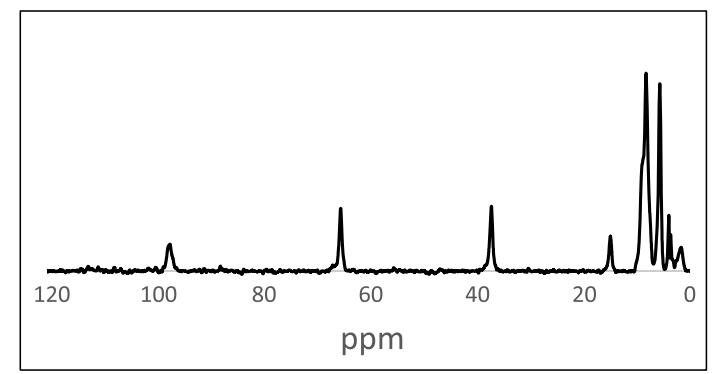

Fig. $8{ }^{1} \mathrm{H}$ paramagnetic spectrum of the solid resulting from the exposure of a slurry of NP1 in hexanes for $6 \mathrm{~h}$ to UV-Vis ( 320 to $700 \mathrm{~nm})$ light, without extraction with methanol. We propose the resulting compound will contain both the salt $\left(\mathrm{Ph}_{3} \mathrm{PCH}_{2} \mathrm{Ph}^{+}\right)_{2}\left(\mathrm{C}_{2} \mathrm{O}_{4}\right)(2)$ and the oligomeric, paramagnetic compound $\left[\mathrm{Co}(\mathrm{II})\left(\mathrm{C}_{2} \mathrm{O}_{4}\right)(\mathrm{bpy})\right]_{n}(\mathbf{3})$ (Fig. $\left.\mathrm{G}\right)$. 


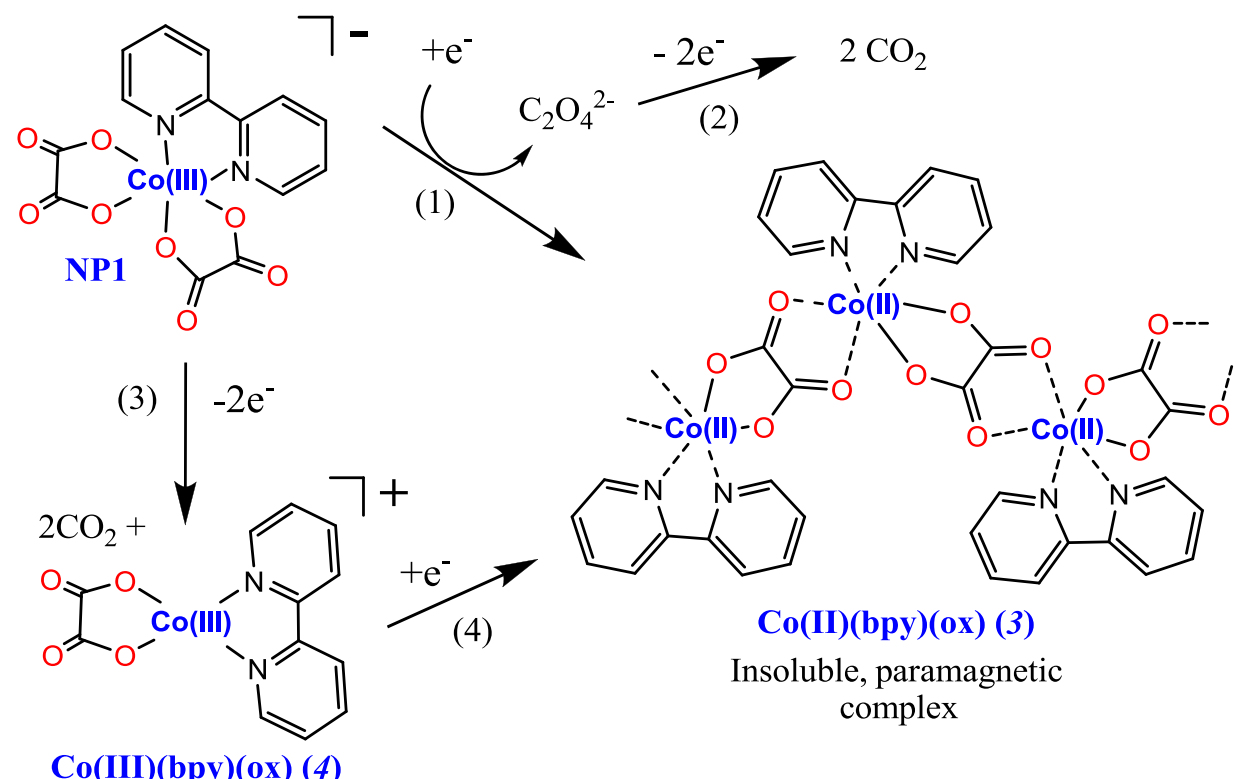

Fig. 9 Summary of proposed electrochemical reactions. For simplicity, the BTP cation, $\mathrm{Ph}_{3} \mathrm{PCH}_{2} \mathrm{Ph}^{+}$, and the product salt, $\left(\mathrm{Ph}_{3} \mathrm{PCH}_{2} \mathrm{Ph}\right)_{2}\left(\mathrm{C}_{2} \mathrm{O}_{4}\right)(2)$ are not shown.

assigned to $\left(\mathrm{PPh}_{3} \mathrm{CH}_{2} \mathrm{Ph}\right)_{2}\left(\mathrm{C}_{2} \mathrm{O}_{4}\right)$ (2) have not undergone the paramagnetic shift. This ${ }^{1} \mathrm{H}$ NMR strongly supports the idea that both compounds $\mathbf{2}$ and $\mathbf{3}$ remain as the nonvolatile products of exposure to UV light (Fig. 9).

\subsection{Electrochemical Studies}

Mechanistic studies of chemically amplified EUV resists show strong evidence for the involvement of both electron trapping and hole-initiated mechanistic pathways for the photolysis of photoacid generators. ${ }^{22}$ Therefore, to gain mechanistic insight into the EUV photoreaction of NP1, we have studied the redox chemistry of acetonitrile solutions of NP1 using cyclic voltammetry (CV). The CV of NP1 exhibits very different results when scanned in the negative direction [first reduction, then oxidation; Fig. [10(a)] or in the positive direction [first oxidation, then reduction; Fig. 10(b)]. There are four different reactions or waves, labeled (1)-(4). Reaction (3) is the only wave common to both directions.

When the scan is initiated in the negative direction [Fig. [10(a)], there is an irreversible reduction of NP1 (1) occurring at $-1.5 \mathrm{~V}$ that we assign to the reduction of $\mathrm{Co}$ (III) to $\mathrm{Co}$ (II). It is irreversible up to $1000 \mathrm{mV} / \mathrm{s}$. The wave (2) at $-0.1 \mathrm{~V}$ is coupled to the $-1.5 \mathrm{~V}$ process. (a)

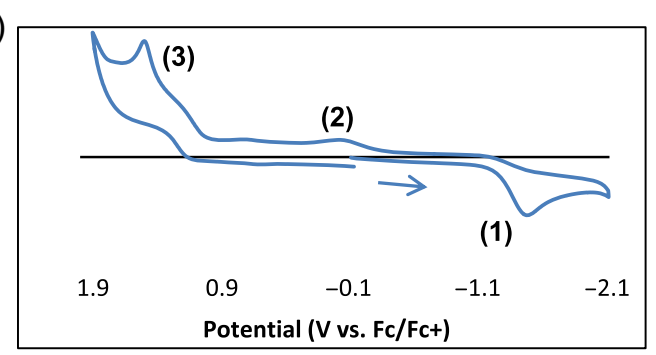

(b)

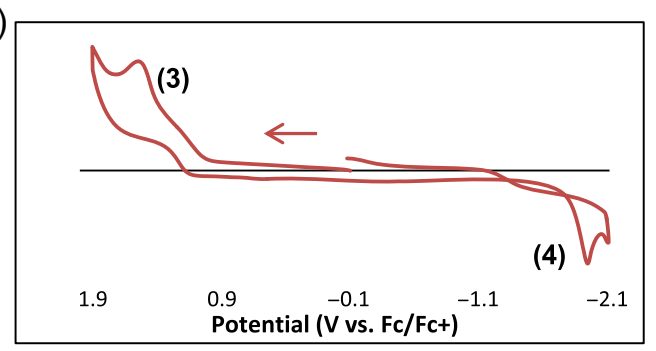

(c)

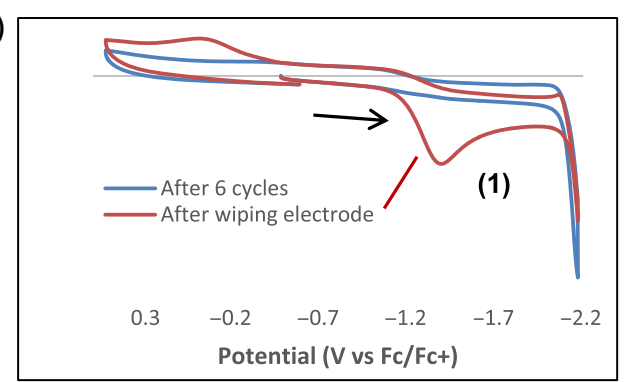

Fig. 10 Cyclic voltammograms of NP1. Both scans were collected at $200 \mathrm{mV} / \mathrm{s}$ scan rate with $0.10 \mathrm{MNBu}_{4} \mathrm{PF}_{6}$ as the supporting electrolyte in acetonitrile. All potentials are relative to $\mathrm{Fc} / \mathrm{Fc}^{+}$. (a) Initiated in the negative direction, (b) initiated in the positive direction, and (c) cyclic voltammogram of $\left[\mathrm{PPh}_{3}\left(\mathrm{CH}_{2} \mathrm{Ph}\right)\right]\left[\mathrm{Co}(\mathrm{bpy})(\mathrm{ox})_{2}\right]$. The blue trace is after 6 cycles with switching potentials of -2.2 and $+0.5 \mathrm{~V}$. The orange trace was collected after cleaning the electrode. 
In other words, reaction (2) only occurs after reaction (1) has occurred. We assign reaction (2) to the irreversible oxidation of free oxalate displaced from the cobalt during the reaction that occurs at (1) by comparison to the work of Chang et al. 23

Figure [10(c) shows that the reduction wave (1) results in the formation of an insoluble product that coats the electrode. Multiple scans from 0.4 to $-2.2 \mathrm{~V}$ cause both the reductive wave (1) and its coupled reoxidation wave (2) to disappear (blue trace). However, cleaning the electrode gives a CV that is nearly identical to the original (red trace).

A somewhat different behavior is observed when the scan is initiated in the positive direction [Fig. 10(b)]. The oxidation wave (3) common to both directions at $+1.5 \mathrm{~V}$ is observed, but the reduction wave (1) originally observed in the negative direction at $-1.5 \mathrm{~V}$ is shifted to (4) $-1.9 \mathrm{~V}$ when going in the positive direction. We think that the oxidation reaction (3) at $+1.5 \mathrm{~V}$ is the result of a cobaltbound oxalate ligand on NP1 undergoing a two-electron oxidation to produce two equivalents of $\mathrm{CO}_{2}$ and the complex $[(\text { bpy }) \mathrm{Co}(\mathrm{III})(\mathrm{ox})]^{+}$(4) (Fig. 9). Then compound $\mathbf{4}$ is reduced to compound $\mathbf{3}$ at $-1.9 \mathrm{~V}$, which then precipitates out onto the electrode resulting in the unusual appearance of the CV trace after the scan switches to the positive direction.

All of the electrochemical reactions are summarized in Fig. 9. When the CV scan is run in the negative direction with a clean electrode and pure NP1 in solution, the oneelectron reduction (1) occurs, producing the insoluble, paramagnetic compound $\mathbf{3}$ and the dissociated oxalate ligand $\left(\mathrm{C}_{2} \mathrm{O}_{4}^{-2}\right)$. Thereafter, the free oxalate anion is oxidized during wave (2) to $\mathrm{CO}_{2}$. When the $\mathrm{CV}$ is run in the positive direction, the cobalt-bound oxalate undergoes a two-electron oxidation to produce two equivalents of $\mathrm{CO}_{2}$ and the diamagnetic $\mathrm{Co}$ (III) complex 4 during wave (3) at $+1.5 \mathrm{~V}$. Thereafter, compound $\mathbf{4}$ is reduced to the insoluble, paramagnetic Co(II) complex 3.

\section{Summary}

Figure 11 summarizes what we believe to be the mechanism for the photochemistry of $\left[\mathrm{PPh}_{3}\left(\mathrm{CH}_{2} \mathrm{Ph}\right)\right]\left[\mathrm{Co}(\mathrm{bpy})(\mathrm{ox})_{2}\right]$. In the first step, an electron is transferred from the oxalate ligand to the cobalt, reducing it from an oxidation state of III to II and forming the oxalate radical anion. This is consistent with mechanistic studies of the photochemistry of metal oxalates in solution. In a second step, a second electron is transferred from the oxalate radical anion to a second equivalent of $\left[\mathrm{Co}(\mathrm{bpy})(\mathrm{ox})_{2}\right]^{-}$, producing a second equivalent of $\mathrm{Co}(\mathrm{bpy})(\mathrm{ox})$, two equivalents of $\mathrm{CO}_{2}(\mathrm{~g})$, and an oxalate anion. The oxalate anion is displaced from the cobalt complex as it is reduced, as we have observed in the $\mathrm{CV}$ experiments. The reduction of two separate metal centers from a single oxalate has precedence from photochemical studies of $\left[\mathrm{Fe}(\mathrm{ox})_{3}\right]^{-3}$. 24 Not shown are the two equivalents of $\mathrm{PPh}_{3}\left(\mathrm{CH}_{2} \mathrm{Ph}\right)^{+}$meaning that the oxalate anion will be present as the salt $\left[\mathrm{PPh}_{3}\left(\mathrm{CH}_{2} \mathrm{Ph}\right)\right]_{2}[\mathrm{ox}]$. Although we do not directly observe this compound, we have observed that the strong match between the IR spectrum of the photoproduct and the synthesized $\operatorname{Co}(\mathrm{bpy})(\mathrm{ox})$ in the oxalate stretching region only occurs after we have washed the photoproduct with methanol, suggesting that another material is present, which contains oxalate and is removed by the methanol. We also know from ${ }^{1} \mathrm{H}-\mathrm{NMR}$ experiments that the $\mathrm{PPh}_{3}\left(\mathrm{CH}_{2} \mathrm{Ph}\right)^{+}$remains unchanged in the photochemical reaction.

We speculate that the relatively efficient photochemistry of this system is due to the nature of how the oxalate reacts. Any reaction that involves charge separation can be stopped by simply having the charges recombine. This can be a very efficient process, particularly in the solid state. In this system, the initial transfer of an electron from oxalate to cobalt produces a very reactive oxalate radical anion that can swiftly reduce another metal center. What is likely a key subsequent step is that after the second electron transfer, two equivalents of $\mathrm{CO}_{2}$ are formed that quickly leave the solid, making the reaction effectively irreversible. This system, overall, combines: (1) a thermodynamically unstable ligand, which is a reducing agent; (2) a metal that can be easily reduced; and (3) products that are rapidly released to prevent back reaction. We believe that these three attributes are useful in designing similar, metal-based resists.

\section{Conclusions}

We have demonstrated that transition metal oxalates can be used to prepare effective EUV photoresists. We believe that this is a very promising platform for continued development
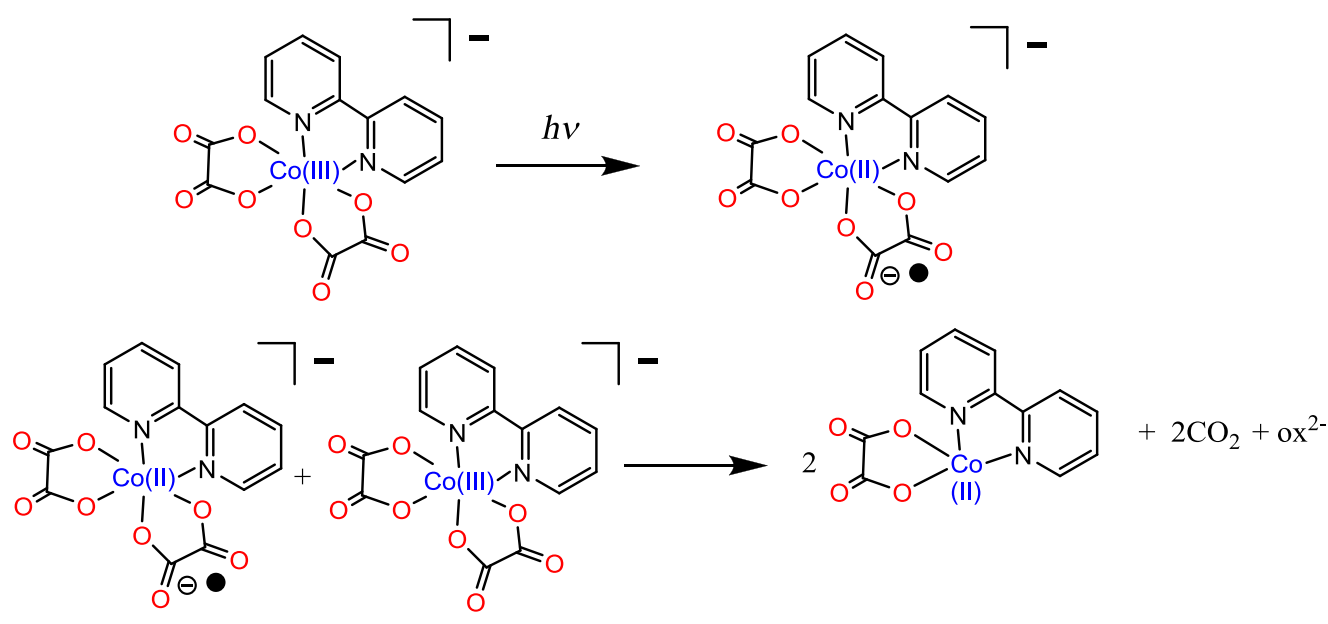

Fig. 11 Proposed photochemical mechanism for the transformation that $\left[\mathrm{PPh}_{3}\left(\mathrm{CH}_{2} \mathrm{Ph}\right)\right]\left[\mathrm{Co}(\mathrm{bpy})(\mathrm{ox})_{2}\right]$ (NP1) undergoes when exposed to EUV light. 
because the counterion the bipyridine ligand and/or the ligand substituents can all be altered to tune the chemical and physical properties of the resist. Given that we can already pattern sub-20-nm lines at relatively low doses, relatively small improvements could make this resist family potentially useful.

\section{Experimental}

General. All reagents were purchased from Sigma Aldrich or Fisher Scientific. All reagents were used as received unless otherwise specified.

Instruments. NMR spectra were obtained using a JEOL Eclipse $+300 \mathrm{MHz}$ spectrometer. All chemical shifts are reported as parts per million (ppm) relative to TMS. CV data were collected on a PAR VersaSTAT 3 potentiostat as previously described Potentials are referenced to ferrocene.

Compound synthesis. $\mathrm{K}_{3}\left[\mathrm{Co}(\mathrm{ox})_{3}\right]^{\text {, }} \mathrm{Na}_{4}\left[\mathrm{Co}_{2}\left(\mathrm{C}_{2} \mathrm{O}_{4}\right)_{4}\right.$ $\left.(\mathrm{OH})_{2}\right] \cdot 5 \mathrm{H}_{2} \mathrm{O}$, $27 \mathrm{~K}\left[\mathrm{Cr}(\mathrm{bpy})(\mathrm{ox})_{2}\right]$, $8 \mathrm{BTP}\left[\mathrm{Fe}(\mathrm{bpy})(\mathrm{ox})_{2}\right]$, $\left.\left.[\mathrm{Co} \text { (bpy) })_{2}(\mathrm{ox})\right] \mathrm{PF}_{6}, \mathrm{BO}[\mathrm{Cr} \text { (bpy) })_{2}(\mathrm{ox})\right] \mathrm{PF}_{6},\left[\mathrm{Fe}(\mathrm{bpy})_{2}(\mathrm{ox})\right]$ $\mathrm{PF}_{6},[1]\left[\mathrm{Co}(\mathrm{bpy})_{3}\right]\left(\mathrm{PF}_{6}\right)_{3}, \mathrm{~B}_{2}\left[\mathrm{Cr}(\mathrm{bpy})_{3}\right]\left(\mathrm{PF}_{6}\right)_{3}$, , $3\left[\mathrm{Fe}(\mathrm{bpy})_{3}\right]$ $\left(\mathrm{PF}_{6}\right)_{3}$, 23 and $\mathrm{Ba}\left[\mathrm{Co}(\mathrm{bpy})(\mathrm{ox})_{2}\right]_{2}$ were prepared using literature procedures. Cationic complexes were metathesized to the $\mathrm{PF}_{6}^{-}$salt by dissolving the chloride salt in water and adding an excess of $\mathrm{NH}_{4} \mathrm{PF}_{6}$ resulting in a precipitate, which was filtered and washed with cold water, methanol, and diethyl ether. Benzyltriphenylphosphium salts of anionic complexes were prepared by dissolving the sodium or potassium salt in water and adding an excess of $\mathrm{P}\left(\mathrm{CH}_{2} \mathrm{Ph}\right)(\mathrm{Ph})_{3} \mathrm{Cl}$ resulting in a precipitate, which was filtered and washed with cold water, methanol, and diethyl ether.

$\left[C o(b p y)_{2}(o x)\right]\left[C o(b p y)(o x)_{2}\right]$. We found the literature preparation for this compound starting with $\mathrm{K}_{3}\left[\mathrm{Co}(\mathrm{ox})_{3}\right]$ to be inconsistent and developed the following procedure using $\mathrm{Na}_{4}\left[\mathrm{Co}_{2}\left(\mathrm{C}_{2} \mathrm{O}_{4}\right)_{4}(\mathrm{OH})_{2}\right] \cdot 5 \mathrm{H}_{2} \mathrm{O}$ as the cobalt source. 2,2'bipyridine $(2.66 \mathrm{~g}, 17.0 \mathrm{mmol})$ was added to $200 \mathrm{~mL}$ of $\mathrm{pH}=5.5,0.87 \mathrm{M}$ acetic acid/sodium acetate buffer solution at $90^{\circ} \mathrm{C}$. To this solution $\mathrm{PbO}_{2}(2.55 \mathrm{~g})$ was added, followed by $\mathrm{Na}_{4}\left[\mathrm{Co}_{2}\left(\mathrm{C}_{2} \mathrm{O}_{4}\right)_{4}(\mathrm{OH})_{2}\right] \cdot 5 \mathrm{H}_{2} \mathrm{O}(4.25 \mathrm{~g}, 5.67 \mathrm{mmol})$ and allowed to react for $12 \mathrm{~min}$ at $90^{\circ} \mathrm{C}$. This mixture was filtered hot to remove a brown solid and the filtrate was placed in an ice bath for $2 \mathrm{~h}$. The resulting purple solid was isolated by filtration, rinsed with water and acetone, and then dried.

$\left[\mathrm{PPh}_{3}\left(\mathrm{CH}_{2} \mathrm{Ph}\right)\right]\left[\mathrm{Co}(\right.$ b py $\left.)(\text { ox })_{2}\right] \quad \mathrm{Ba}\left[\mathrm{Co}(\mathrm{bpy})(\mathrm{ox})_{2}\right]_{2}$ $(1.5 \mathrm{~g}, 1.63 \mathrm{mmol})$ was added to a solution containing $\left(\mathrm{NH}_{4}\right)_{2} \mathrm{SO}_{4}(0.4932 \mathrm{~g}, 3.73 \mathrm{mmol})$ in $15 \mathrm{~mL}$ of water. This mixture was stirred for $30 \mathrm{~min}$ then filtered through diatomaceous earth in a Buchner funnel to remove the $\mathrm{BaSO}_{4}$. Benzyltriphenylphosphonium chloride (1.93 g, $4.96 \mathrm{mmol})$ was added to the purple filtrate and stirred with gentle heating for $30 \mathrm{~min}$, cooled in an ice bath for $2 \mathrm{~h}$ resulting in a purple precipitate. The product was purified by recrystallization from methanol and diethyl ether yielding purple needless. Yield $33 \%$.

Preparative scale photolysis of NP1. NP1 (199 mg) was placed into a pyrex tube with $10 \mathrm{~mL}$ of hexane and a stir bar. The tube was sealed with a septum, and the solution was purged with argon. The slurry was photolysed for $6 \mathrm{~h}$ with the output from a 200-W Hg vapor lamp during which time the dark red of the NP1 turned to a light orange color. The orange product was isolated by filtration, yielding $170 \mathrm{mg}$. Washing the product with cold methanol yielded a more intensely colored orange product with the concomitant loss of about $50 \%$ of the mass.

Resist formulation and imaging. Resist formulations were made by dissolving solids in a suitable solvent at 2 to $3 \mathrm{wt}$. $\%$ solids and filtering through a $0.2-\mu$ m polytetrafluoroethylene filter. Formulations were then spin-cast onto 4-in. silicon wafers, precoated with a crosslinked underlayer (cross-linked hydroxyethyl methacrylate/methyl methacrylate copolymers). This underlayer was crosslinked during a $200^{\circ} \mathrm{C} / 2$ min $\mathrm{PAB}$ and used a thermal acid generator (King Industries) and an acid-catalyzed crosslinker. The purpose of this underlayer was to improve coating quality and adhesion. No unusual photochemical interactions between underlayer and resist were expected or observed. Except where noted, no postapplication or postexposure bakes were used because: (1) no benefits were observed when bakes were used and (2) the thermal stability of these unique thin films were unknown. Resist film thicknesses were typically 50 to $60 \mathrm{~nm}$ for contrast curves and $\sim 30 \mathrm{~nm}$ for imaging. Unlike polymeric resists, the film thicknesses of these molecular organometallic resists are not very sensitive to spin-speeds. Instead, film thicknesses are primarily varied by changing the $\%$ solids of the compound in the resist solution. In most cases, film thicknesses were measured using profilometry.

Resist films were exposed with 13.5-nm radiation and developed with MEK for anionic compounds and alcohols, such as 2-propanol, for cationic complexes. In general, we utilize developers that clear unexposed resist films in 10 to $60 \mathrm{~s}$. Two exposure tools were used for this study: the Berkeley direct contrast tool (DCT) and the PSI EUV interferometer The sensitivity of the image exposures at PSI was calibrated to be as close to doses by pattering an open-source CAMP resist (OS-2) $)^{34}$ at both facilities and correcting to the mask doses obtained at PSI to the waferplane doses obtained at Berkeley. All LER values were obtained from the analysis of the SEM micrographs in SuMMIT Lithography Image Analysis software.

\section{Acknowledgments}

We would like to thank Sematech for financial support of this work. We would like to thank DuPont for supplying us with ESCAP polymer used in the preparation of the calibration resist $\mathrm{OS}^{34}$ and King Industries for supplying us with a thermal acid generator for the crosslinked underlayer. Finally, we would like to thank Patrick Naulleau at the Lawrence Berkeley National Laboratory for providing us with SuMMIT Lithography Image Analysis software. Part of this work was performed at Swiss Light Source, Switzerland.

\section{References}

1. J. M. Amador et al., "Patterning chemistry of $\operatorname{HafSO}_{x}$ photoresist," Proc. SPIE 9051, 90511A (2014).

2. M. Trikeriotis et al., "Development of an inorganic photoresist for DUV, EUV, and electron beam imaging," Proc. SPIE 7639, 76390E (2010),

3. J. W. Thackeray, "Materials challenges for sub-20-nm lithography," J. Micro/Nanolithogr. MEMS MOEMS 10(3), 033009 (2011).

4. C. A. Mack et al., "Stochastic exposure kinetics of extreme ultraviolet photoresists: simulation study," J. Micro/Nanolithogr. MEMS MOEMS 10(3), 033019 (2011).

5. B. Cardineau et al., "Photolithographic properties of tin-oxo clusters using extreme ultraviolet light (13.5 nm)," Microelectron. Eng. 127, $44-50,(2014)$

6. B. Cardineau et al., "EUV resists based on tin-oxo clusters," Proc. SPIE, 9051, 90511B (2014). 
7. J. Passarelli et al., "Bismuth resists for EUV lithography," J. Photopolym. Sci. Technol. 27(5), 655-661 (2014).

8. J. Passarelli et al., "Organometallic carboxylate resists for extreme ultraviolet with high sensitivity," J. Micro. Nanolithogr. MEMS MOEMS, 14(4), 043503 (2015).

9. M. Sortland et al., "Platinum and palladium oxalates: positive-tone extreme ultraviolet resists," J. Micro. Nanolithogr. MEMS MOEMS, 14(4), 043511 (2015).

10. R. Del Re et al., "Low-line edge roughness extreme ultraviolet photoresists of organotin carboxylates," J. Micro. Nanolithogr. MEMS MOEMS, 14(4), 043506 (2015).

11. E. L. Simmons and W. W. Wendlandt, "Solid-state photochemical reactions of transition-metal coordination compounds" Coord. Chem. Rev. 7(1), 11-27 (1971)

12. A. L. Poznyak and V. I. Pavlovski, "Photochemical reactions of ligands in transition metal complexes," Angew. Chem. 100(6), 812-819 (1988).

13. A. W. Adamson et al., "Photochemistry of transition-metal coordination compounds," Chem. Rev. 68(5), 541-585 (1968).

14. Y. Ekinci et al., "Evaluation of EUV resist performance with interference lithography towards $11 \mathrm{~nm}$ half-pitch and beyond," Proc. SPIE 8679, 867910 (2013).

15. N. Tanaka and M. Nanjo, "The thermal decomposition of metal oxalato complexes," Bull. Chem. Soc. Jpn. 40(2), 330-333 (1967).

16. S. Grzeskowiak et al., "Reactivity of metal-oxalate EUV resists as a function of the central metal," Proc. SPIE, 10146, 1014605 (2017).

17. The UV-Vis exposures were conducted using a $200-\mathrm{W}$ mercury vapor lamp filtered by a Pyrex tube. The exposure range is $\sim 320-700 \mathrm{~nm}$.

18. K. Nakamoto, Infrared and Raman Spectra of Inorganic and Coordination Compounds: Part B: Applications in Coordination, Organometallic and Bioinorganic Chemistry, 6th ed., John Wiley \& Sons, Inc., Hoboken, New Jersey (2009).

19. A. Dubraja et al., "The influence of metal centres on the exchange interaction in heterometallic complexes with oxalate-bridged cations," Dalton Trans. 46(35), 11748-11756 (2017).

20. D. M. Duggan and D. N. Hendrickson, "Magnetic exchange interactions in transition metal dimers. IV. High-spin cobalt(II)-2,2',2"-triaminotriethylamine complexes with oxalate inner-sphere and cyanate, thiocyanate, chloride, and azide outer-sphere bridges," Inorg. Chem. 14(8), 1944-1956 (1975).

21. J. Kang et al., "1D and 2D Cobalt(II) coordination polymers, Co(ox) (en): synthesis, structures and magnetic properties," Bull. Korean. Chem Soc. 35, 3244-3248 (2014).

22. A. Narasimhan et al., "Mechanisms of EUV exposure: electrons and holes," Proc. SPIE, 10143, 101430W (2017).

23. M.-M. Chang, T. Saji, and A. J. Bard, "Electrogenerated chemiluminescence. 30. Electrochemical oxidation of oxalate ion in the presence of luminescers in acetonitrile solutions," J. Am. Chem. Soc. 99(16), 53995403 (1977).

24. C. A. Parker and C. G. Hatchard, "Photodecomposition of complex oxalates - some preliminary experiments by flash photolysis," J. Phys. Chem. 63(1), 22-26 (1959).

25. D. D. Graf and K. R. Mann, "Electrochemical investigation of ruthenium and osmium oligothiophene complexes: how does metal binding affect the oligothiophene $\pi$-system?" Inorg. Chem. 36(2), 150-157 (1997)

26. J. C. Bailar, Jr and H. S. Booth, Inorganic Synthesis, Vol. 1, McGrawHill, New York (1939).

27. A. M. Sargeson and I. K. Reid, "Potassium tetraoxalato-di- $\mu$ hydroxodicobaltate (III) trihydrate (Durrant's salt) and sodium tetraoxalato-di- $\mu$-hydroxodicobaltate(III) pentahydrate," Inorg. Synth., 8, 204-207 (1966).

28. J. Broomhead, "The preparation and resolution of the bis(oxalato)-2,2'bipyridinechromate(III) and bis(oxalato)-1,10-phenanthrolinechromate (III) ions," Aust. J. Chem. 15, 228-231 (1962).

29. D. Armentano et al., "Bis and tris(oxalato)ferrate(III) complexes as precursors of polynuclear compounds," CrystEngComm 7(7), 57-66 (2005).

30. J. A. Broomhead, M. Dwyer, and N. Kane-Maguire, "Synthesis and resolution of heterochelate metal complexes of chromium(III) and cobalt (III) with the ligands 2,2'-bipyridine, 1,10-phenanthroline, and oxalate ion," Inorg. Chem. 7(7), 1388-1393 (1968).

31. S. K. Bajpai and P. R. Shukla, "Screening of metal complexes for biological activity. Part II: structural and biological studies on iron(II) oxalate complexes with various nitrogen donors," J. Ind. Chem. Soc. 57(2), 219-221 (1980).

32. F. H. Burstall and R. S. Nyholm, "Cöordination chemistry. XIII. Magnetic moments and bond types of transition-metal complexes ," J. Chem. Soc. (Resumed) (0), 3570-3579 (1952).

33. A. Hauser et al., "Electronic and molecular structure of tris(2,2'bipyridine)chromium(3+)," Inorg. Chem. 26(8), 1331-1338 (1987).

34. C. D. Higgins et al., "Resolution, line-edge roughness, sensitivity tradeoff, and quantum yield of high photo acid generator resists for extreme ultraviolet lithography," Jpn. J. Appl. Phys. 50(3), 036504 (2011).

Miles Wilklow-Marnell did his bachelor's work at SUNY New Paltz before obtaining his PhD at the University of Rochester, working on carbon-atom bond activation by organometallic complexes of iridium, in the lab of Professor William D. Jones. He returned to SUNY New Paltz in 2017 and joined the faculty as an assistant professor. His research interests include inorganic/organometallic catalysis, photochromic ligands, and materials applications of inorganic/organometallic compounds.

Robert L. Brainard received his BS degree in chemistry from U.C. Berkeley. He studied the reaction mechanisms of organoplatinum compounds during his graduate studies with Professor G. Whitesides at MIT and Harvard University. Following his postdoctoral studies with Professor R. Madix at Stanford University, he worked for Polaroid and Shipley/RHEM in the areas of DUV and EUV. He is now a professor at CNSE, investigating new materials for use in EUV lithography and for biological applications.

Daniel A. Freedman received his BA degree in chemistry from Macalester College and his PhD in inorganic chemistry from the University of Minnesota with Professor Kent Mann. He joined the faculty in the chemistry department at SUNY New Paltz in 1999. In 2012 he was appointed dean of the School of Science and Engineering and director of the Hudson Valley Advanced Manufacturing Center at SUNY New Paltz in 2013. His research interests include the synthesis and photochemistry of inorganic compounds.

Biographies of the other authors are not available. 